\title{
Patient attitudes and understanding about biosimilars: an international cross-sectional survey
}

\author{
This article was published in the following Dove Press journal: \\ Patient Preference and Adherence \\ 26 May 2016 \\ Number of times this article has been viewed
}

\author{
Ira Jacobs' \\ Ena Singh ${ }^{2}$ \\ K Lea Sewell ${ }^{3}$ \\ Ahmad AL-Sabbagh' \\ Lesley G Shane'
}

'Global Established Pharma Medicines Development Group, Pfizer Inc., New York, NY, ${ }^{2}$ Global Medical Affairs, Pfizer Inc., Collegeville, PA, ${ }^{3}$ Biotechnology Clinical Development, Pfizer Inc., Cambridge, MA, USA
Correspondence: Ira Jacobs Global Established Pharma Medicines Development Group, Pfizer Inc., 235 East 42nd Street, New York, NY 10017-5755, USA

Tel +I 2127330876

Email ira.jacobs@pfizer.com
Objective: To understand the levels of awareness, usage, and knowledge of biosimilars among patients, caregivers, and the general population in the US and the European Union; perceptions of biosimilars compared to originator biologics; perceived benefits and drawbacks of clinical trials; and whether advocacy groups impact patients' willingness to try a biosimilar.

Methods: An international survey was conducted which contained up to 56 closed-ended (requiring yes/no or ranking answers) and open-ended questions, depending on the population assigned. The survey was divided into distinct sections, including medication-class awareness, usage, and knowledge about biologic and biosimilar therapies; perceptions of clinical trials; and involvement in advocacy groups. Interviews were conducted in adults categorized as: 1) diagnosed: patients with inflammatory bowel disease including Crohn's disease and ulcerative colitis, rheumatoid arthritis, psoriasis, breast cancer, lung cancer, colorectal cancer, or nonHodgkin's lymphoma; 2) diagnosed advocacy: individuals with these diseases who participated in patient support groups; 3 ) caregiver: has a loved one with these conditions and is involved in medical decisions; 4) general population: aged 18-64 years, without these conditions. Statistical analyses among groups within a region (US or EU) used column proportions test with a 95\% confidence interval.

Results: In all, 3,198 individuals responded. Awareness about biologic therapies was significantly higher in diagnosed, diagnosed advocacy, and caregiver groups (45\%-78\%) versus general population $(27 \% ; P<0.05)$. Across all groups, awareness of biosimilars was low; only $6 \%$ of the general population reported at least a general impression of biosimilars. Awareness was significantly higher in the diagnosed advocacy group $(20 \%-30 \% ; P<0.05)$. Gaps in knowledge about biosimilars included safety, efficacy, and access to these agents. Respondents had generally positive perceptions of clinical trials, although barriers to participation were identified.

Conclusion: An immediate need exists for patient education about biosimilars and clinical trials to ensure educated and informed decisions are made about biosimilar use.

Keywords: patient education, cancer, treatment, biologic therapy, biosimilar, advocacy groups, inflammatory disease, oncology

\section{Introduction}

In March 2015, the US Food and Drug Administration (FDA) approved the first biosimilar product, filgrastim-sndz (Zarxio ${ }^{\circledR}$; Sandoz Inc., Holzkirchen, Germany), for the same indications as the originator product, filgrastim (Neupogen ${ }^{\circledR}$; Amgen Inc., Thousand Oaks, CA, USA). ${ }^{1}$ Outside the US, several biosimilars are approved under guidelines adopted by the European Medicines Agency, Health Canada, and the World Health Organization. ${ }^{2-4}$ Thus, biosimilars are an increasingly available treatment option for many diseases. Several additional biologic therapies have upcoming patent expirations; therefore, approval of more biosimilars is expected. In anticipation 
of these approvals, an increased need for patient education exists so that patients can make informed decisions about biosimilars as treatment options. Topics for patient education about biosimilars and biologic therapies should include the definition of a biosimilar and how they differ from smallmolecule generics, regulatory approval of biosimilars, the potential impact biosimilars may have on disease treatment by increased access to care, and knowledge of and enrollment in clinical trials for biosimilars.

The term "biosimilar" refers to a biologic product developed such that there are no clinically meaningful differences between the biosimilar and an existing licensed, originator biologic in terms of efficacy, safety, and immunogenicity. ${ }^{4-6}$ Both originator biologics and biosimilars are typically large, structurally complex proteins; even minor changes in manufacturing processes can produce posttranslational structural differences. ${ }^{4,5}$ In contrast, the term "generic medicines" refers to small-molecule drugs, typically synthesized using chemical processes with demonstrated structural equivalence to the originator small-molecule product. ${ }^{4}$ As a result, biosimilars cannot be considered identical or generic equivalents to the originator biologic. ${ }^{4,5}$ Thus, the regulatory process for biosimilar approval is not the same as that used for smallmolecule generics and regulatory agencies have developed specific guidelines for biosimilar approval..$^{2-5,7}$

Despite significant efficacy in many indications, access to and the number of patients able to benefit from biologic therapies is limited due to costs. ${ }^{8}$ Biosimilars have the potential for improving patient care through savings and efficiencies for the health care system, increased access to biologic therapies, and broadening the number of treatment options available. As a result, availability of biosimilars could lead to expanded use of biologic therapies overall, which may result in better health outcomes.

Since an understanding of current patient awareness and knowledge is critical to development of patient education programs, we conducted a survey on biosimilars and biologic therapies. The objectives were to gain a baseline understanding of awareness, usage, and knowledge of biosimilars among patients, caregivers, and the general population in the US and the European Union (EU); uncover initial perceptions of biosimilars in comparison to originator biologics; to understand perceived benefits and drawbacks of clinical trials for future biosimilar testing; and identify whether advocacy groups impact patient willingness to try a biosimilar. This survey was conducted prior to the approval of any biosimilars in the US (although respondents could receive biosimilars through participation in clinical trials).
So, differences were expected in awareness and attitudes versus the EU where biosimilars have been available for several years.

\section{Methods \\ Respondents}

Interviews were conducted from April 24 to May 19, 2014 in the US and the EU which included UK, France, Spain, Germany, and Italy. A random subset of individuals was selected by the recruiting agency using a random number generator and screened. Individuals were aged 18 years or older and recruited online from a nationally representative sample for each country (general population) or online and offline (diagnosed, diagnosed advocacy, and caregiver groups). No minimum education was required. Respondents had to be able to read the native language of the country in which they lived (English, French, German, Italian, or Spanish).

The following populations were included:

- Diagnosed: Patients who had inflammatory bowel disease including Crohn's disease and ulcerative colitis, rheumatoid arthritis, or psoriasis (moderate to severe only; severity was self-reported by respondents) for $\geq 6$ months and had seen a doctor in past 12 months about the particular condition, or who have had breast, lung, or colorectal cancer, or non-Hodgkin's lymphoma in the past 2 years.

- Diagnosed advocacy: Patients with the above-described diseases who had participated in support groups. These respondents were separate from the diagnosed group, not a subset.

- Caregiver: Individuals involved in decisions or dialogue about medication or therapy options for a loved one with these conditions.

- General population: Individuals, aged 18-64 years, neither having any of the listed diseases nor having loved ones with these conditions; there was no limit for any other diseases in this group. The upper age limit was set to represent the general population, which tends to be younger than people with the diseases listed. No attempt was made to match respondents in this group to demographics of the patient or caregiver groups; nationally representative demographic targets were set for each country.

\section{Survey}

The survey was conducted through online (desktop or laptop computers only) interviews by an independent survey company (Lieberman Research Worldwide, Los Angeles, CA, USA; for questions regarding this survey, please contact Lieberman 
Research Worldwide at Biosimilars@1rwonline.com) and contained up to 56 questions, depending on the population assigned. Each interview ranged from 10 to 20 minutes, depending on group assignment and the country in which the respondent lived. The survey consisted of a series of closed-ended questions requiring yes/no or ranking answers and open-ended questions conducted in the native language of the country in which they lived (English, French, German, Italian, or Spanish). The surveys were translated for each country by professional translators. Once translated, a second translator reviewed the text to match the intent of the English language.

The survey was divided into distinct sections, including medication-class awareness, usage, and knowledge about biologic and biosimilar therapies; perceptions of clinical trials; and involvement in advocacy groups. At the start of the survey, all respondents were assessed for their baseline awareness. Following this, all respondents were presented with definitions of biologics and biosimilars in the section evaluating medication awareness, usage, and knowledge. Perceptions about biologics and biosimilars were determined after the definition was provided. Respondents were also asked to indicate which attributes describe biologics and biosimilars very well in the section evaluating the perceptions of safety, efficacy, and access/use. The survey was based on respondent recall and personal opinions. Questions were pretested for understanding and interpretation, but not repeat validity.

\section{Analysis}

Statistical analyses were conducted among the diagnosed, diagnosed advocacy, caregiver, and general population groups in a region (US or EU) using the column proportions test, with a 95\% confidence interval. France, Spain, Germany, Italy, and UK respondents were combined for the EU region. Due to the small sample size within each country in the EU, no statistical analyses were performed between countries. The column proportions test compares pairs of columns and assesses whether proportions of respondents in one column are significantly different from the other column. ${ }^{9}$ No statistical analyses were conducted for positive and negative perceptions between patient subgroups aware or unaware of biosimilars, in either region.

\section{Results}

A total of 3,198 respondents were interviewed (Table 1); qualification rate of participants was not specifically determined, but was $\sim 12 \%$ based on targeted efforts in the US. Demographics were generally similar among groups (Table S1). More respondents were from the combined EU

Table I Respondents

\begin{tabular}{|c|c|c|c|c|c|c|c|c|c|c|}
\hline & \multicolumn{5}{|l|}{ US, $n$} & \multicolumn{5}{|c|}{ European Union, n } \\
\hline & Diagnosed $^{a}$ & $\begin{array}{l}\text { Diagnosed } \\
\text { advocacy }\end{array}$ & Caregiver $^{c}$ & $\begin{array}{l}\text { General } \\
\text { population }^{\mathrm{d}}\end{array}$ & Total & Diagnosed $^{a}$ & $\begin{array}{l}\text { Diagnosed } \\
\text { advocacy }^{b}\end{array}$ & Caregiver $^{c}$ & $\begin{array}{l}\text { General } \\
\text { population }^{\mathrm{d}}\end{array}$ & Total \\
\hline $\begin{array}{l}\text { General } \\
\text { population }\end{array}$ & 0 & 0 & 0 & 250 & 250 & 0 & 0 & 0 & 499 & 499 \\
\hline \multicolumn{11}{|c|}{ Inflammatory diseases } \\
\hline $\begin{array}{l}\text { Inflammatory } \\
\text { bowel disease }\end{array}$ & 147 & 54 & 26 & 0 & 227 & 240 & 60 & 50 & 0 & 350 \\
\hline $\begin{array}{l}\text { Rheumatoid } \\
\text { arthritis }\end{array}$ & 150 & 52 & 25 & 0 & 227 & 241 & 60 & 50 & 0 & 351 \\
\hline Psoriasis & 150 & 50 & 25 & 0 & 225 & 240 & 60 & 51 & 0 & 351 \\
\hline $\begin{array}{l}\text { Total inflammatory } \\
\text { diseases }\end{array}$ & 447 & 156 & 76 & 0 & 679 & 721 & 180 & $|5|$ & 0 & 1,052 \\
\hline \multicolumn{11}{|l|}{ Oncology } \\
\hline Breast cancer & 76 & 16 & 7 & 0 & 99 & 120 & 15 & 13 & 0 & 148 \\
\hline Lung cancer & 53 & 27 & 7 & 0 & 87 & 60 & 14 & 10 & 0 & 84 \\
\hline $\begin{array}{l}\text { Non-Hodgkin's } \\
\text { lymphoma }\end{array}$ & 19 & 20 & 10 & 0 & 49 & 24 & 11 & 10 & 0 & 45 \\
\hline $\begin{array}{l}\text { Hodgkin's } \\
\text { lymphoma }\end{array}$ & 5 & 10 & 4 & 0 & 19 & 24 & 13 & 10 & 0 & 47 \\
\hline Colorectal cancer & 35 & 16 & 7 & 0 & 58 & 60 & 12 & 10 & 0 & 82 \\
\hline Total oncology & 188 & 89 & 35 & 0 & 312 & 288 & 65 & 53 & 0 & 406 \\
\hline Overall total & 635 & 245 & 111 & 250 & $|, 24|$ & 1,009 & 245 & 204 & 499 & 1,957 \\
\hline
\end{tabular}

Notes: 'Diagnosed with inflammatory bowel disease including Crohn's disease and ulcerative colitis, rheumatoid arthritis, or psoriasis (moderate to severe only) for $\geq 6$ months and had seen the doctor in past 12 months about the particular condition, or have had breast cancer, lung cancer, colorectal cancer, or non-Hodgkin's lymphoma in past 2 years. 'Diagnosed with any of the listed diseases and had heard of and participated in patient support groups. 'Has a loved one with any of the listed diseases and is involved in decisions or dialogue about medication or therapy options. Individuals aged 18-64 years without any of the listed diseases or loved ones with these conditions. 
countries $(n=1,957 ; 61.2 \%)$ than from the US $(n=1,241$; $38.8 \%)$. Approximately two-thirds of respondents $(n=2,134$; $66.7 \%$ ) were in the diagnosed or diagnosed advocacy groups (ie, patients). The proportion of respondents in these groups was slightly higher in the US $(n=880 ; 70.9 \%)$ than in the EU $(n=1,254 ; 64.1 \%)$. The majority of respondents from the combined diagnosed, diagnosed advocacy, and caregiver groups had or had a loved one with an inflammatory disease $(n=1,731 ; 70.7 \%)$, whereas $<30 \%$ had or had a loved one with cancer $(n=718 ; 29.3 \%)$. Attitudes and awareness of caregivers generally reflected those of the diagnosed/ diagnosed advocacy groups; therefore, detailed results from the caregiver group are not presented.

\section{Biologic therapy}

The percentage of respondents reporting at least a "general awareness" of biologics (defined as reporting at least a general impression of biologics or knew the term "biologic") was higher among all the patient groups than in the general population; participation in advocacy groups further increased awareness of biologics (Table 2). Specifically, a higher percentage of respondents in the diagnosed advocacy versus diagnosed groups reported at least a general impression of biologics $(P<0.05)$ or knew the term "biologic" $(P<0.05)$. In comparison with the general population, differences in the percentage of respondents reporting at least a general impression of biologics were significant for both the diagnosed and diagnosed advocacy groups $(P<0.05)$, whereas the percentage of those reporting they knew the term "biologic" was significantly higher only in the US diagnosed advocacy group $(P<0.05)$. Conversely, the percentage of respondents reporting they had never heard of biologics was significantly lower in the diagnosed advocacy groups than in the diagnosed and general population groups $(P<0.05$ for both comparisons). Differences between diagnosed and general population groups were also significant $(P<0.05)$. Participation in advocacy groups was associated with a significant increase in the percentage of respondents reporting current use of biologic therapies, compared with patients not currently participating in support groups $(P<0.05)$.

\section{Biosimilars}

Awareness of biosimilars was less across all groups in both US and EU respondents, with only 6\%-30\% reporting at least a general impression and up to $70 \%$ reporting they had never heard of biosimilars (Table 2). Awareness was significantly higher in the diagnosed advocacy versus diagnosed $(P<0.05)$ and general population $(P<0.05)$ groups. The percentage of respondents reporting at least a "general impression of biosimilars" was higher in the EU diagnosed group than in the

Table 2 Awareness and current use of biologic therapies and biosimilars

\begin{tabular}{|c|c|c|c|c|c|c|}
\hline & \multicolumn{3}{|l|}{ US, \% } & \multicolumn{3}{|c|}{ European Union, \% } \\
\hline & $\begin{array}{l}\text { General } \\
\text { population }^{a} \\
n=250\end{array}$ & $\begin{array}{l}\text { Diagnosed }^{b} \\
n=635\end{array}$ & $\begin{array}{l}\text { Diagnosed } \\
\text { advocacyc } \\
n=245\end{array}$ & $\begin{array}{l}\text { General } \\
\text { population }^{a} \\
n=499\end{array}$ & $\begin{array}{l}\text { Diagnosed }^{b} \\
n=1,009\end{array}$ & $\begin{array}{l}\text { Diagnosed } \\
\text { advocacyc }^{c} \\
n=245\end{array}$ \\
\hline \multicolumn{7}{|l|}{ Biologic therapy } \\
\hline \multicolumn{7}{|l|}{ Awareness ${ }^{\mathrm{d}, \mathrm{e}}$} \\
\hline Has at least a general impression & II & $30^{A}$ & $47^{\mathrm{A}, \mathrm{B}}$ & 10 & $19^{A}$ & $43^{\mathrm{A}, \mathrm{B}}$ \\
\hline Just know the name & 16 & 19 & $\left.3\right|^{A, B}$ & 17 & $26^{A}$ & $29^{A}$ \\
\hline Not sure & 17 & $17^{c}$ & 12 & $22^{B, C}$ & 18 & 15 \\
\hline Never heard of it & $57^{\mathrm{B}, \mathrm{C}}$ & $33^{c}$ & 10 & $50^{\mathrm{B}, \mathrm{C}}$ & $37^{c}$ & 12 \\
\hline Currently use & N/A & 18 & $29^{\mathrm{B}}$ & N/A & 9 & $3 I^{B}$ \\
\hline \multicolumn{7}{|l|}{ Biosimilar therapy } \\
\hline \multicolumn{7}{|l|}{ Awareness $\mathrm{d}^{\mathrm{d}, \mathrm{e}}$} \\
\hline Has at least a general impression & 6 & 9 & $20^{\mathrm{A}, \mathrm{B}}$ & 6 & $\mathrm{II}$ & $30^{\mathrm{A}, \mathrm{B}}$ \\
\hline Just know the name & 10 & $16^{A}$ & $27^{A, B}$ & 10 & $19^{A}$ & $3 I^{A, B}$ \\
\hline Not sure & 14 & $2 I^{A}$ & $23^{\mathrm{A}}$ & 19 & 22 & 19 \\
\hline Never heard of it & $70^{\mathrm{B}, \mathrm{C}}$ & $54^{c}$ & 31 & $66^{\mathrm{B}, \mathrm{C}}$ & $49^{c}$ & 20 \\
\hline Currently use ${ }^{f}$ & $\mathrm{~N} / \mathrm{A}$ & 2 & $9^{B}$ & N/A & 5 & $22^{B}$ \\
\hline \multicolumn{7}{|c|}{$\begin{array}{l}\text { Notes: aged I8- } 64 \text { years without any of the listed diseases or loved ones with these conditions. 'Diagnosed with inflammatory bowel disease including Crohn's disease and } \\
\text { ulcerative colitis, rheumatoid arthritis, or psoriasis (moderate to severe only) for } \geq 6 \text { months and had seen their doctor in past } 12 \text { months about the particular condition, } \\
\text { or who have had breast cancer, lung cancer, colorectal cancer, or non-Hodgkin's lymphoma in past } 2 \text { years. "Diagnosed with any of the listed diseases and had heard of and } \\
\text { participated in patient support groups. 'Defined as reporting at least a general impression of biologics or knew the term "biologic" or "biosimilars". eNot all categories sum } \\
\text { to } 100 \% \text { due to rounding. 'Use could include during participation in clinical trials at the time of the survey. }{ }^{A} p<0.05 \text { for the column proportions test in comparison to the } \\
\text { general population group in the same region. }{ }^{B} P<0.05 \text { for the column proportions test in comparison to the diagnosed group in the same region. }{ }^{C} P<0.05 \text { for the column } \\
\text { proportions test in comparison to diagnosed advocacy group in the same region. }\end{array}$} \\
\hline
\end{tabular}


general population $(P<0.05)$, whereas those reporting they knew the term "biosimilar" was significantly higher among US and EU respondents $(P<0.05)$. Current use of biosimilars was significantly higher among US and EU respondents in the diagnosed advocacy groups compared with the diagnosed groups $(P<0.05)$.

\section{Biosimilar safety and efficacy perceptions}

Several gaps in perceptions about biosimilars were noted between patients who were aware of biosimilars and those who were unaware (ie, those who answered "never heard of biosimilar"), regardless of their participation in advocacy groups. A higher percentage of patients who were aware of biosimilars reported positive perceptions of biosimilars than the respondents who were unaware of biosimilars (Figure 1). The gaps in perceptions were generally consistent among US and EU patients who were aware or unaware of biosimilars.

Overall, the widest gap in perceptions was for efficacy. Specifically, higher percentages of patients aware of biosimilars agreed with the statement "biosimilars are the best option to treat the patient's condition" than the patients who were unaware. Similarly, the percentage of patients agreeing that biosimilars effectively treat their condition was higher among patients who were aware of biosimilars versus patients who were unaware.

Wide gaps in the perception of safety were also noted among patients aware of biosimilars than those unaware of them. The largest and most consistent gap was agreement with the statement "biosimilars are safe", with more patients who were aware of biosimilars agreeing with this statement. A wide difference in the percentage of patients who were comfortable switching to this medication also existed, with more patients who were aware of biosimilars agreeing with this statement. Although the gap was somewhat less, differences in the percentage of patients agreeing with the statement "biosimilars have minimal side effects" were also noted.

Differences in the perceptions about access and price of biosimilars were also considerable. The percentage of patients who agreed that biosimilars are affordable was much lower in the group of patients unaware of biosimilars versus those who were aware of them. The percentage of patients agreeing with the statement "biosimilars provide effective care at reasonable cost" was much higher among patients who were aware versus those who were unaware of biosimilars.

\section{Biosimilar safety and efficacy perceptions versus biologics}

When patients who were aware of biosimilars were asked about their perception of biosimilars relative to biologics, additional gaps were noted (Figure 2). Perception about safety and efficacy of biologics was slightly higher than for biosimilars, whereas perception about access and price favored biosimilars. The gaps overall were consistent among US and EU patients, but the gaps in perceptions about price and access were somewhat higher among EU respondents.

The widest gap in perception among patients aware of biosimilars was in regard to efficacy. The percentage of

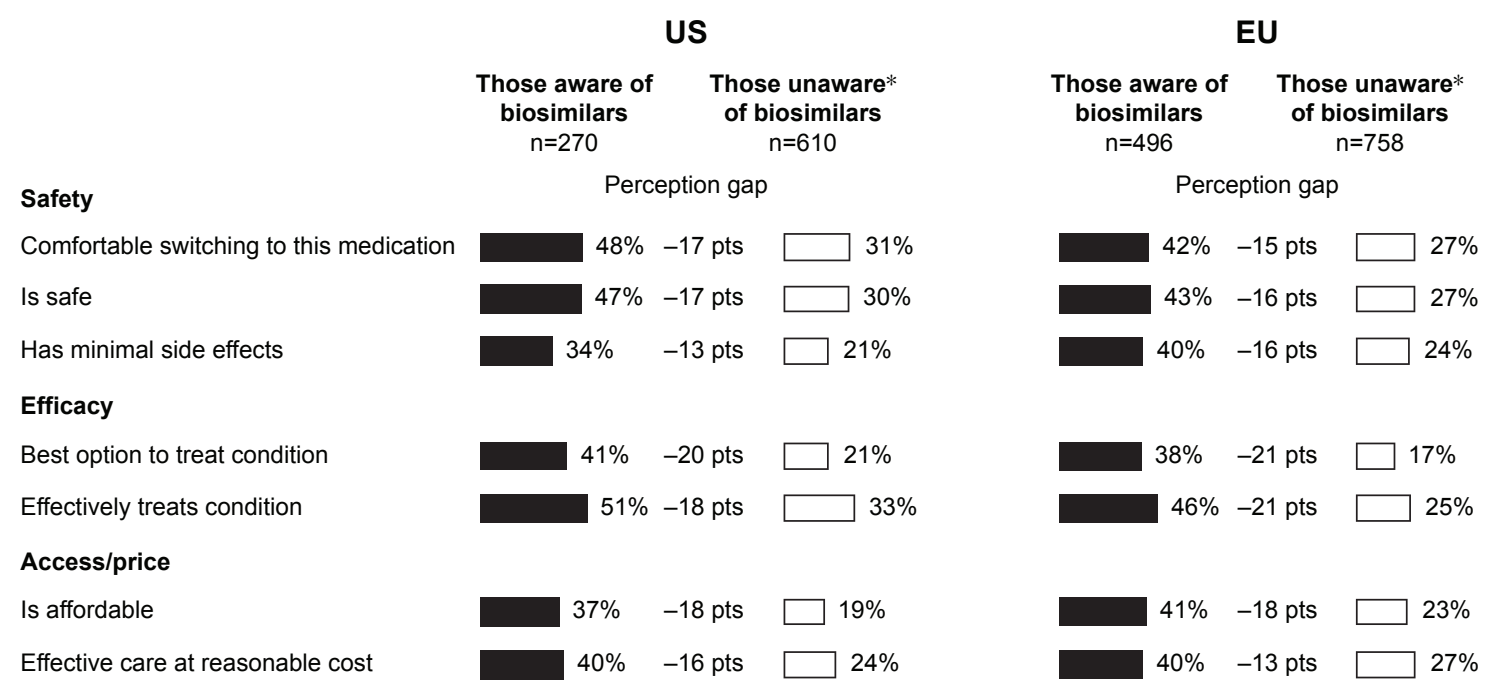

Figure I Gaps in perceptions about biosimilars among patients aware of and those unaware of biosimilars.

Notes: *Unaware = answered "never heard of biosimilar" in response to the question, "Which of the following types of medications have you heard of before today?" No statistical analyses were conducted between patients aware and those unaware of biosimilars.

Abbreviations: EU, European Union; pts, patients. 


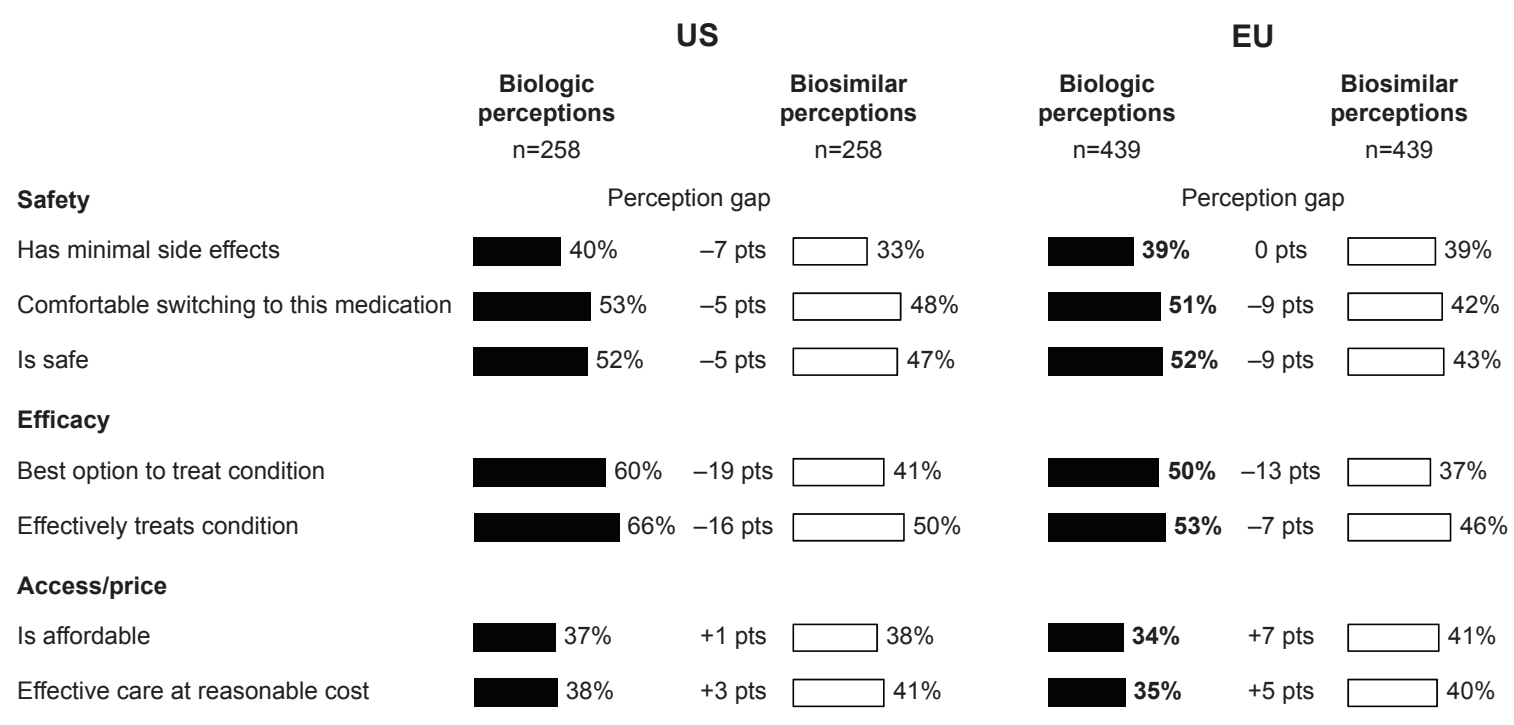

Figure 2 Gaps in perceptions about biosimilars compared to biologic therapies among patients aware of biosimilars. Note: No statistical analyses were conducted between groups.

Abbreviations: EU, European Union; pts, patients.

respondents agreeing "biologics are the best option to treat the patient's condition" was higher than those agreeing "biosimilars are the best option". Likewise, a higher percentage of respondents agreed "biologics effectively treat [their] condition" than that of those who agreed the same for biosimilars. Although there were gaps in the perceptions of safety favoring biologics, these gaps were narrower than for efficacy. More respondents agreed that biologics have minimal side effects, were comfortable switching to biologics, and that biologics are safe versus biosimilars. As noted, perception about access and price of biosimilars was higher than for biologics. The percentage of patients who agreed with "biosimilars are affordable" and "biosimilars provide effective care at reasonable cost" also was higher than for biologics.

\section{Clinical trial perceptions}

Overall, the respondents had positive perceptions of clinical trials. More than half of the respondents agreed with the statement that clinical results are dependable. More than two-thirds of respondents agreed that clinical trials are important for advancing what we know about disease treatment, allow patients the opportunity to meet with specialists, and are worth their (patients') time. Many respondents from the diagnosed group were willing to participate in clinical trials: $24 \%$ of respondents from the US and $31 \%$ from the EU stated they were either "very interested" or "extremely interested" to participate in a clinical trial. More US and EU patients with inflammatory diseases (31\% and 37\%, respectively) expressed willingness to participate in clinical trials, compared to patients with cancer $(21 \%$ and $31 \%$, respectively).

The top three potential benefits that the respondents listed for clinical trial participation were: opportunities to gain access to new treatments for their condition, participation in the advancements of disease treatments, and playing an active role in their own health care. In contrast, perceived barriers led to $22 \%-30 \%$ of patients reporting no interest in joining a clinical trial. The top three reasons that the patients listed were: concerns about side effects, assignment to a placebo rather than active treatment, and time commitments required for participation.

Involvement in advocacy groups increased interest in participating in clinical trials. Compared with patients who did not participate in advocacy groups, the percentage of respondents from the diagnosed advocacy group who responded they were either "very interested" or "extremely interested" in participating in a clinical trial was significantly higher among both US $(38 \% ; P<0.05)$ and EU $(43 \% ; P<0.05)$ patients. However, involvement in advocacy groups did not influence overall attitudes about clinical trial participation. The most common potential benefits and perceived barriers were the same as those reported by respondents in the diagnosed group.

\section{Factors influencing willingness to try biosimilars}

One important factor that influenced patients' willingness to try a biosimilar was the manufacturer of that biosimilar. Among respondents in the diagnosed group, 28\%-29\% 
reported that the manufacturer's identity was "very influential" in their decision and another 10\%-14\% reported this was "extremely influential" in this decision. Among patients in the diagnosed advocacy group, manufacturer identity was an even greater factor in the decision to be prescribed a particular drug, whereas $46 \%-48 \%$ of respondents indicated the biosimilar manufacturer was "very" or "extremely" influential in their decision. Similarly, the manufacturer conducting a clinical trial was also considered a factor in the decision for patient involvement in clinical trials.

\section{Discussion}

This survey indicates several areas in which additional education about biosimilars, biologic therapies, and potential treatment options are necessary. Many respondents reported at least a general awareness of biologics, which was higher among respondents in the diagnosed advocacy versus the diagnosed groups; both groups had greater knowledge than the general population. These differences were not surprising since many patient advocacy groups are developed to provide support and education for patients. ${ }^{10}$ Likewise, differences between patient groups and the general population likely reflect patient education by health care providers as part of disease treatment. However, a good portion of respondents in all groups had never heard of biologics, indicating there remains an unmet need for education about this class of drugs. Although not directly analyzed for significance, differences in the percentage of patients having a general awareness about biologics versus those just knowing the name may be due to differences in direct-to-consumer advertising in the US and the EU.

Awareness levels about biosimilars were similar to those reported for biologic therapies. However, overall awareness was much lower (vs biologics) among all respondents, indicating there is a great need for patient education about biosimilars across all groups. As with general awareness about biologics, awareness of biosimilars was significantly higher among respondents in the diagnosed advocacy group than in other groups, probably due to education programs. Again, although not compared statistically, some differences were noted in awareness about biosimilars among US and EU respondents. More EU versus US respondents in the diagnosed and diagnosed advocacy groups reported a general impression or knowing the name "biosimilar" or "current use" of a biosimilar. This is likely due to the fact that the survey was conducted prior to the recent US FDA approval of the first biosimilar (filgrastim-sndz; although respondents could receive biosimilars through participation in clinical trials), ${ }^{1}$ whereas biosimilars have been available in the EU since 2006. ${ }^{11}$ Another factor that may cause reduced awareness of biosimilars compared with biologic therapies is that patient information leaflets in some countries do not identify products as biosimilars. ${ }^{12}$

The results reported in the current analysis are similar to those of a recent survey conducted by the American Autoimmune Related Diseases Association of 362 members (96\% of whom reported living with an autoimmune disease) in which $\sim 52 \%$ did not understand how biologics differ from chemical drugs and $>80 \%$ did not know what biosimilar medicines were. ${ }^{13}$ Taken together, these results indicate that patients need more education about biologic and biosimilar therapies.

The low awareness of biosimilars may be creating gaps in patient perceptions that impact their willingness to be prescribed biosimilar treatment. We identified several educational or informational topics that health care providers should discuss with patients, so that the patients could make informed decisions on treatment and overall care (Table 3 ). For example, patients need some basic information about the regulatory requirements for demonstration of similar efficacy and safety of biosimilars compared with the originator (ie, licensed or marketed) biologic, so that they understand there is no clinically meaningful difference in efficacy or safety between the two treatments. ${ }^{14,15}$ This should help to alleviate any patient misconceptions that reductions in cost indicate that quality is not comparable. Similarly, patients need information about other factors that may impact their decisions, such as access and product use. ${ }^{16}$ In addition, some patients have reservations about taking biologic therapies in

Table 3 Checklist for health care providers of the information needed for patients to make informed decisions about biosimilar use/health care

\begin{tabular}{|c|c|}
\hline $\begin{array}{l}\text { Discussed } \\
\text { with patient? }\end{array}$ & Topic \\
\hline & Use of biologic therapies in the specific disease \\
\hline & Definition of a biosimilar \\
\hline & Totality of evidence required of a biosimilar \\
\hline & Efficacy similar to innovator biologic \\
\hline & Safety similar to innovator biologic \\
\hline & Delivery/administration of the agent \\
\hline & Device use (if applicable) \\
\hline & Access to treatment \\
\hline & Insurance coverage and out-of-pocket cost \\
\hline & Services available to support the patient \\
\hline & $\begin{array}{l}\text { Clinical trials including standard biosimilar trial design } \\
\text { (active innovator comparator; no placebo arm) }\end{array}$ \\
\hline & Manufacturer identity \\
\hline
\end{tabular}


general and may be hesitant to take biosimilars because they are biologic drugs. Therefore, it is important that patient education packages include materials about the use of biologics in the treatment of their disease. Since caregiver perceptions generally reflect those of patients, education regarding biologic therapies and biosimilars should be developed in parallel to those of patients.

One potential resource for developing and expanding patient education is through partnerships between health care providers and advocacy groups. Many advocacy groups were developed out of a need to provide patient support and education and so, they are considered important stakeholders in patient education. ${ }^{17}$ Partnerships with advocacy groups may help educate patients who are already more engaged, more opinionated, and have relatively positive attitudes toward biosimilars, such as those represented by respondents in the diagnosed advocacy group in this study. However, all patients, regardless of their involvement with advocacy, will benefit through these partnerships.

A key area in which to develop informative educational programs concerns clinical trial participation. Overall, respondents had positive perceptions of clinical trials. The perceived barriers and reasons cited by patients who reported hesitancy about joining a clinical trial (ie, concerns about side effects, being assigned to a placebo, time commitments required for participation, maintenance of adequate response, and trust) were generally similar to those reported in past surveys of patient attitudes toward clinical research in cancer and noncancer trials. ${ }^{18-20}$ One difference noted in the current survey as compared with earlier surveys was between patients with cancer versus those with inflammatory diseases regarding their willingness to participate in clinical trials. In this survey, more patients with inflammatory diseases expressed willingness to participate in clinical trials. This may be due to misconceptions about required randomization to placebo treatment in biosimilar clinical trials, since this was a major reason reported for nonparticipation in prior surveys. ${ }^{19}$ Since all biosimilar clinical trials for patients with active disease involve comparison only to the active comparator (originator biologic) with no placebo arm, this is a clear-cut area for educational activity. Alternatively, differences in willingness may reflect distinctions in patient needs in these conditions, including changing standard of care for biosimilar trials.

Specific patient educational information is needed regarding participation in clinical trials, particularly those investigating potential biosimilars. ${ }^{20}$ In the survey, about one-third to one-half of patients diagnosed with cancers responded hesitantly because they responded, "I'm not guaranteed to be on an active medication". This finding from the survey suggests that patients' education about clinical trials of potential biosimilars should include only the active medications (eg, standard care in a therapeutic area) of both the active originator and the active potential biosimilar to compare efficacy and safety. This clarification should help to alleviate hesitancy to participate due to concerns that the patient may not be administered an active medication. Patients also need to understand that by the time potential biosimilars reach Phase III clinical trials, a considerable amount of evidence already demonstrates similarity to the originator biologic. Products approved under the stringent requirements of the European Medicines Agency, FDA, Health Canada, or the World Health Organization biosimilar pathways have a considerable amount of data supporting similarity to the originator biologic, and regulatory decisions for approval are based on the "totality of the evidence" supporting the biosimilar in comparison to the originator (Figure S1). ${ }^{3-5,7}$

As described in a recent review by Socinski et al, ${ }^{21}$ the current pathways for regulatory approval of a biosimilar typically include a stepwise approach with extensive stateof-the-art characterization (analytical) studies and nonclinical studies, as well as a tailored clinical trial program to assess and confirm similarity of the potential biosimilar to the originator. Since patient benefit was demonstrated through the clinical studies conducted for the originator, the focus of the clinical program for biosimilars is to show similarity of the potential biosimilar to the originator. It is important to remember that clinical trials for potential biosimilars specifically designed to confirm similarity generally include only the potential biosimilar and the originator for comparison, with no placebo group. As a result, health care providers involved in clinical trials should be well informed about the expected efficacy and safety of a potential biosimilar, since these should be similar to the marketed originator.

Since involvement in an advocacy group impacts patients' willingness to participate in clinical trials, a partnership between health care providers and advocacy groups may be beneficial for patient care and treatment decisions. ${ }^{10,17}$ In addition, since the results of this survey indicated that manufacturer identity is an important factor influencing willingness to be prescribed a biosimilar or participate in a clinical trial, partnerships between advocacy groups and biosimilar developers may be beneficial for both parties in the development of patient education materials, as well as increasing enrollment in clinical trials. ${ }^{10,17}$ 
Limitations to this study were the differences in some demographics between patient and caregiver groups versus the general population, including access to and prior use of biologics and biosimilars, limited geographic distribution of respondents, conducting the survey only on laptop or desktop computers, requirement that respondents be able to read the native language of the country in which they lived, the use of closed-ended questions in the survey, and the lack of repeat validity testing.

\section{Conclusion}

Gaps exist in knowledge and perceptions about the use of biologic and biosimilar therapies in disease treatment. Patient education programs, developed in partnership with advocacy groups should provide patients with the necessary information to make informed decisions about the use of these products. Additional studies and follow-ups could be conducted to determine whether and how attitudes change with education.

\section{Acknowledgments}

Medical writing support was provided by Christina McManus, PhD, of Engage Scientific Solutions, and funded by Pfizer Inc. The data was accepted as an abstract and poster for presentation at the International Society for Pharmacoeconomics and Outcomes Research 18th Annual European Congress (ISPOR-EU), November 7-11, 2015, Milan, Italy. This study was sponsored by Pfizer Inc. The sponsor contributed to the design and conduct of the study, collection and analysis of data, and review of the manuscript. This study was a survey and no interventions were administered; written informed consent and ethics committee (EC)/institutional review board (IRB) approval were not required. In agreement with the journal policy, the authors declare they confirm all patient/personal identifiers have been removed or disguised, so that the patient/person(s) described are not identifiable and cannot be identified through the details of the paper.

\section{Author contributions}

All authors were responsible for the interpretation of the data, the final content of the manuscript, and the decision to submit for publication. All authors have made substantial contributions to this manuscript including all of the following: 1) the conception and design of the study, acquisition of data, and/ or analysis and interpretation of data, 2) drafting the article or revising it critically for important intellectual content, and 3) final approval of the version to be submitted.

\section{Disclosure}

Ira Jacobs, Ena Singh, K Lea Sewell, and Lesley G Shane are current employees of Pfizer Inc. and hold stock or stock options in Pfizer Inc. Ahmad AL-Sabbagh was an employee of Pfizer Inc. at the time of conducting this study and holds stock or stock options in Pfizer Inc. The authors report no other conflicts of interest in this work.

\section{References}

1. US Food and Drug Administration [homepage on the Internet]. FDA approves first biosimilar product Zarxio [FDA news release]. US Food and Drug Administration; 2016 [updated March 6, 2016]. Available from: http://www.fda.gov/NewsEvents/Newsroom/PressAnnouncements/ ucm436648.htm. Accessed March 23, 2016.

2. European Medicines Agency [homepage on the Internet]. Guideline on similar biological medicinal products containing monoclonal antibodies non-clinical and clinical issues [report]. London: European Medicines Agency Committee for Medicinal Products for Human Use (CHMP); 2010 [updated May 30, 2012]. Available from: http://www.ema. europa.eu/docs/en_GB/document_library/Scientific_guideline/2012/06/ WC500128686.pdf. Accessed August 25, 2015.

3. Health Canada [homepage on the Internet]. Guidance for Sponsors: Information and Submission Requirements for Subsequent Entry Biologics (SEBS) [report]. Ottawa, ON, Canada: Health Products and Food Branch, Health Canada; 2010 [updated March 5, 2010]. Available from: http://www.hc-sc.gc.ca/dhp-mps/alt_formats/pdf/brgtherap/applicdemande/guides/seb-pbu/seb-pbu-2010-eng.pdf. Accessed August 25, 2015.

4. World Health Organization [homepage on the Internet]. Guidelines on Evaluation of Similar Biotherapeutic Products (SBPS) [report]. Geneva, Switzerland: World Health Organization Expert Committee on Biological Standardization; 2009 [updated October 19, 2009]. Available from: http://www.who.int/biologicals/areas/biological_therapeutics/ BIOTHERAPEUTICS_FOR_WEB_22APRIL2010.pdf. Accessed April 7, 2015.

5. US Food and Drug Administration [homepage on the Internet]. Scientific Considerations in Demonstrating Biosimilarity to a Reference Product: Guidance for Industry [report]. Silver Spring, MD: US Department of Health and Human Services, Center for Drug Evaluation and Research (CDER), Center for Biologics Evaluation and Research (CBER); 2015 [updated April 2015]. Available from: http://www.fda.gov/downloads/ Drugs/GuidanceComplianceRegulatoryInformation/Guidances/ UCM291128.pdf. Accessed April 7, 2015.

6. European Medicines Agency [homepage on the Internet]. Guideline on Similar Biological Medicinal Products [report]. London: European Medicines Agency Committee for Medicinal Products for Human Use (CHMP); 2014 [updated October 23, 2014]. Available from: http://www.ema. europa.eu/docs/en_GB/document_library/Scientific_guideline/2014/10/ WC500176768.pdf. Accessed June 5, 2015.

7. European Medicines Agency [homepage on the Internet]. Guideline on Similar Biological Medicinal Products Containing BiotechnologyDerived Proteins as Active Substance: Non-Clinical and Clinical Issues. Draft [report]. London: European Medicines Agency Committee for Medicinal Products for Human Use (CHMP); c2013 [updated June 3, 2013]. Available from: http://www.ema.europa.eu/docs/en_GB/document_library/Scientific_guideline/2013/06/WC500144124.pdf. Accessed August 25, 2015.

8. Vital EM, Kay J, Emery P. Rituximab biosimilars. Expert Opin Biol Ther. 2013;13(7):1049-1062.

9. IBM Corporation [homepage on the Internet]. Column Proportions Test [user guide]. Armonk, NY: IBM Corporation; 2013 [updated 2013]. Available from: http://www-01.ibm.com/support/knowledgecenter/ SSLVQG_7.0.0/com.spss.reportsforsurveys/column_proportions_test. htm?lang=en. Accessed May 13, 2015. 
10. Nijsten T, Bergstresser PR. Patient advocacy groups: let's stick together. J Invest Dermatol. 2010;130(7):1757-1759.

11. Generics and Biosimilars Initiative (GaBi) Online [homepage on the Internet]. Biosimilars approved in Europe [global news report]. Mol, Belgium: Pro Pharma Communications International; 2011 [updated February 27, 2015]. Available from: http://www.gabionline. net/Biosimilars/General/Biosimilars-approved-in-Europe. Accessed April 21, 2015.

12. European Biopharmaceutical Enterprises. Tell me the whole story: the role of product labelling in building user confidence in biosimilars in Europe. GaBi J. 2014;3(4):1-6.

13. American Autoimmune Related Diseases Association [homepage on the Internet]. Leading Autoimmune Patient Advocacy Group Survey Finds Overwhelming Majority of Patients Lack Understanding of Biosimilar Drugs [media release]. New York, NY: Carway Communications, Inc; 2015 [updated February 11, 2015]. Available from: http://www.aarda. org/wp-content/uploads/2015/02/BiosimilarsWhitePaperPressRelease. pdf. Accessed March 10, 2015.

14. Colbert RA, Cronstein BN. Biosimilars: the debate continues. Arthritis Rheum. 2011;63(10):2848-2850.
15. Kozlowski S, Woodcock J, Midthun K, Sherman RB. Developing the nation's biosimilars program. N Engl J Med. 2011;365(5):385-388.

16. Sarpatwari A, Avorn J, Kesselheim AS. Progress and hurdles for follow-on biologics. N Engl J Med. 2015;372(25):2380-2382.

17. Patient advocates: expanding their role in conducting successful clinical trials. J Oncol Pract. 2006;2(6):298-299.

18. Madsen SM, Holm S, Davidsen B, Munkholm P, Schlichting P, Riis P. Ethical aspects of clinical trials: the attitudes of participants in two non-cancer trials. J Intern Med. 2000;248(6):463-474.

19. Madsen SM, Mirza MR, Holm S, Hilsted KL, Kampmann K, Riis P. Attitudes towards clinical research amongst participants and nonparticipants. J Intern Med. 2002;251(2):156-168.

20. Rompas S, Goss T, Amanuel S, et al. Demonstrating value for biosimilars: a conceptual framework. Am Health Drug Benefits. 2015;8(3):129-139.

21. Socinski MA, Curigliano G, Jacobs I, Gumbiner B, MacDonald J, Thomas D. Clinical considerations for the development of biosimilars in oncology. MAbs. 2015;7(2):286-293. 


\section{Supplementary materials}

Table SI Demographics

\begin{tabular}{|c|c|c|c|c|c|c|c|c|}
\hline & \multicolumn{4}{|l|}{ US, $n$} & \multicolumn{4}{|c|}{ European Union, n } \\
\hline & Diagnosed $^{a}$ & $\begin{array}{l}\text { Diagnosed } \\
\text { advocacy }^{\text {b }}\end{array}$ & Caregiver $^{c}$ & $\begin{array}{l}\text { General } \\
\text { population }^{\mathrm{d}}\end{array}$ & Diagnosed $^{a}$ & $\begin{array}{l}\text { Diagnosed } \\
\text { advocacy }^{b}\end{array}$ & Caregiver $^{c}$ & $\begin{array}{l}\text { General } \\
\text { population }\end{array}$ \\
\hline \multicolumn{9}{|l|}{ Sex, \% } \\
\hline Male & 35 & 37 & 44 & 49 & 46 & 53 & 47 & 47 \\
\hline Female & 65 & 63 & 56 & 51 & 54 & 47 & 53 & 53 \\
\hline Mean age, years, \% & 52.9 & 45.8 & 48.7 & 41.9 & 39.6 & 44.7 & 42.7 & 43.8 \\
\hline $18-24$ & 4 & 6 & 5 & 13 & 5 & 9 & 6 & 8 \\
\hline $25-34$ & 15 & 24 & 24 & 21 & 22 & 33 & 22 & 17 \\
\hline $35-44$ & 14 & 19 & 14 & 18 & 24 & 27 & 29 & 26 \\
\hline $45-54$ & 19 & 18 & 15 & 26 & 23 & 17 & 26 & 26 \\
\hline $55-64$ & 27 & 22 & 24 & 22 & 18 & 11 & 13 & 23 \\
\hline $65-74$ & 15 & 9 & 14 & 0 & 7 & 2 & 4 & 0 \\
\hline $75+$ & 5 & 2 & 4 & 0 & I & 0 & 0 & 0 \\
\hline \multicolumn{9}{|l|}{ Country, \% } \\
\hline USA & 100 & 100 & 100 & 100 & 0 & 0 & 0 & 0 \\
\hline UK & 0 & 0 & 0 & 0 & 27 & 26 & 16 & 20 \\
\hline France & 0 & 0 & 0 & 0 & 17 & 14 & 25 & 20 \\
\hline Germany & 0 & 0 & 0 & 0 & 18 & 21 & 13 & 25 \\
\hline Spain & 0 & 0 & 0 & 0 & 17 & 16 & 26 & 15 \\
\hline Italy & 0 & 0 & 0 & 0 & 20 & 23 & 21 & 20 \\
\hline
\end{tabular}

Notes: aDiagnosed with inflammatory bowel disease including Crohn's disease and ulcerative colitis, rheumatoid arthritis, or psoriasis (moderate to severe only) for $\geq 6$ months and had seen the doctor in past 12 months about the particular condition, or have had breast cancer, lung cancer, colorectal cancer, or non-Hodgkin's lymphoma in past 2 years. bDiagnosed with any of the listed diseases and had heard of and participated in patient support groups. 'Has a loved one with any of the listed diseases and is involved in decisions or dialogue about medication or therapy options. Individuals aged 18-64 years without any of the listed diseases or loved ones with these conditions. ${ }^{\mathrm{N}} \mathrm{Not}$ all categories sum to $100 \%$ due to rounding. 


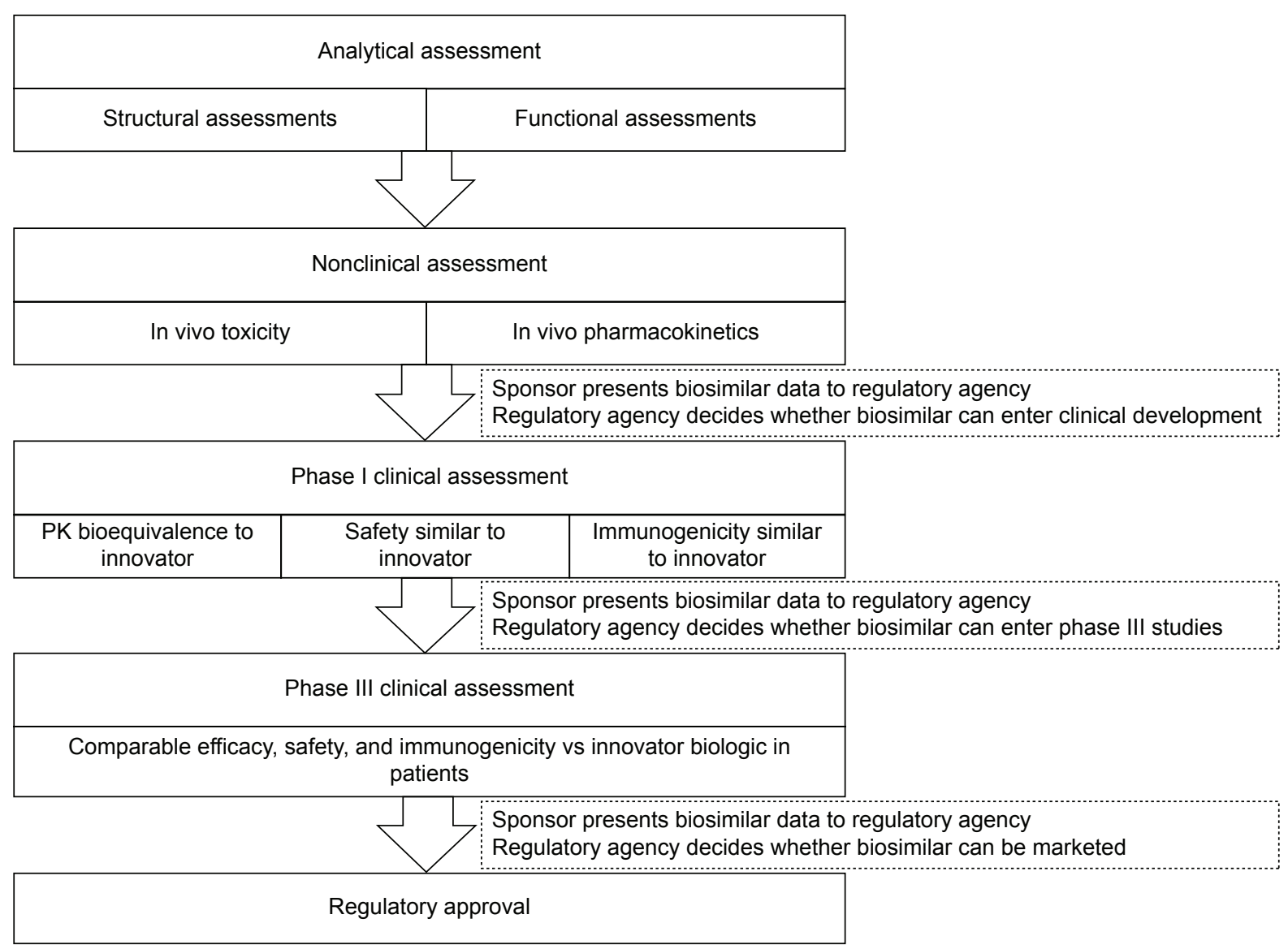

Figure SI Approval process for biosimilars.

\section{Publish your work in this journal}

Patient Preference and Adherence is an international, peer-reviewed, open access journal that focuses on the growing importance of patient preference and adherence throughout the therapeutic continuum. Patient satisfaction, acceptability, quality of life, compliance, persistence and their role in developing new therapeutic modalities and compounds to optimize clinical outcomes for existing disease states are major areas of interest for the journal. This journal has been accepted for indexing on PubMed Central. The manuscript management system is completely online and includes a very quick and fair peer-review system, which is all easy to use. Visit http://www. dovepress.com/testimonials.php to read real quotes from published authors.

Submit your manuscript here: http://www.dovepress.com/patient-preference-and-adherence-journal 